Transexualidade: o corpo entre o sujeito e a ciência Jorge, M. A. C., \& Travassos, N. Rio de Janeiro, RJ: Zahar, 2018, 149 págs.

\title{
Espelho, espelho meu, diga-me de qual sexo sou eu!
}

\section{Mirror, mirror of mine, tell me what sex I am!}

Dercirier Gonçalves Freire*1

Em Transexualidade: o corpo entre o sujeito e a ciência a epígrafe inicial, "O homem se define pelo que o inquieta, não pelo o que assegura" - frase de Elie Wiesel —, anuncia que a inquietação estará presente nas trilhas traçadas pelos autores. São muitas as inquietações, que partem de interrogações e deixam-nos com desafios. Dentre esses, está a necessidade de focarmos o fenômeno da transexualidade pelas vias social e cultural. O impossível da complementaridade entre os sexos é a inquietação presente no humano e que ressoa por todo o livro. Assunto presente nos meios acadêmicos e midiáticos, $\mathrm{o}$ debate sobre a transexualidade encontra adeptos e opositores. Brasil).

*1 Corpo Freudiano Escola de Psicanálise, Seção Rio de Janeiro (Rio de Janeiro, RJ, 


\section{RESENHAS BIBLIOGRÁFICAS}

Nesse importante momento de discussão do tema na sociedade, os psicanalistas Marco Antonio Coutinho Jorge e Natália Travassos lançam o presente livro de escrita leve e elucidativa, que não se propõe a apresentar soluções estanques, mas levar o leitor à reflexão.

Um livro com rigor histórico e científico que mostra um estudo minucioso do tema em diversos campos do saber como antropologia, medicina, psicanálise, psicologia e sociologia. Ainda que não seja um livro de teoria psicanalítica, é a psicanálise que alinhava as diversas questões evidenciando a necessidade de se escutar o sujeito em sua singularidade. Há que se olhar para o sintoma e não reduzir o sujeito a ele. Sentir-se desconfortável com a própria sexualidade é um sintoma a ser ouvido.

Já na introdução, os autores alertam para a banalização dos procedimentos transexualizadores e que, em sua grande maioria, são irreversíveis. Também deixam claro que não legitimam nenhuma forma de patologização de quaisquer orientações de ordem sexual ou identidade de gênero.

No capítulo "Interrogações", os autores afirmam que o sujeito não se reduz ao corpo. O sujeito tem um corpo, ainda que esse corpo the traga inquietudes. Lembram que o enigma da histeria é a "singular falta da correspondência objetiva entre a materialidade do corpo e a subjetividade" (p. 19). O capítulo termina com a interrogação sobre para que e para quem serve a adequação corporal oferecida pela ciência.

No segundo capítulo, "Sexo e gênero", é tratado o enigma da diferença sexual com o esclarecimento sobre o que é a sexualidade em Freud e sua importância na espécie humana. Sob ação da linguagem, a sexualidade humana não está a serviço da reprodução. Capazes de investir libidinalmente em objetos de ambos os sexos, os humanos possuem bissexualidade psíquica. Nesse capítulo, distingue-se com muita clareza sexo de gênero. O primeiro diz respeito à anatomia do corpo e o segundo a uma construção cultural. Sexo é da ordem do real do corpo e gênero da ordem do simbólico e do imaginário.

Em “A questão sexual”, é feito um rico passeio pela história daqueles que não se adequavam ao padrão homem/mulher desde os Citas, povo nômade que viveu entre a Ásia Central e a Rússia nos séculos VIII e VII a.C. Através de importantes trechos da história da transexualidade é mostrada a cunhagem do termo "transexualismo". Este provém do psychopatia transexualis termo usado pelo médico David O. Cauldwell, em 1949, que significava o desejo mórbido, patológico de ser um indivíduo completo do sexo oposto. O termo transexualismo, criado em 1953 pelo endocrinologista Harry Benjamin, migrou para a psiquiatria em 1973. Atualmente, é catalogado na Classificação 
Internacional de Doenças (CID-10) como "transexualismo" e no Diagnostic and Statistical Manual of Mental Disorders (DSM-5) como "disforia de gênero".

Dentre as indagações dos autores sobre esse diagnóstico, destaco: como um diagnóstico psiquiátrico pode ser tratado pela via cirúrgica? As cirurgias transexuais não são garantia de apaziguamento para o sujeito, tampouco seu caráter irreversível impede a busca da reversibilidade ao sexo biológico anterior. Além disso, há casos de depressão e suicídio pós-tratamento da transexualidade.

Um problema de suma importância é trazido no livro: o diagnóstico e o tratamento transexualizador em crianças. Se o processo de transexualização em adultos abarca dúvidas e angústias, em crianças e adolescentes a situação é ainda mais preocupante. Até que ponto as angústias dos pais são determinantes no diagnóstico da transexualidade infantil? Ressaltam os autores que nenhuma criança se define como transgênero. São os adultos que as rotulam dessa forma e recebem a ratificação dos "especialistas".

Em consonância com os diagnósticos, emerge a questão da homofobia. Historicamente, o homossexual enfrenta condições de discriminação seja por si mesmo, seja pelo Outro. Presente em todos os países, o horror à homossexualidade encontra, de acordo com cada cultura e a leis pátrias, posturas das mais diversas. As pressões sociais e familiares influenciam decisões de diversos homossexuais, desde esconder sua homossexualidade até negá-la para si mesmos. "Pagar o preço da homossexualidade não é para qualquer um" (p. 118). A transexualidade pode ocupar uma função apaziguadora nesse angustiante lugar homofóbico.

A cristalização imaginária refletida no espelho plano da ciência, erigido sob predeterminações sociais do que é "coisa de homem" ou é "coisa de mulher" inviabiliza que cada sujeito se reconheça além do seu órgão sexual. Nesse aspecto, a psicanálise aposta na possibilidade de dialetizar as fixações imaginárias de sentido. Permite, assim, a utilização de recursos simbólicos para abrandar a inquietude do impossível do real do sexo através do seu descolamento imaginário do corpo.

Ao fim do livro, os autores indagam para que serve tentar adequar o corpo à alma. Entretanto, deixam o leitor com uma certeza: a resposta recebida para as inquietudes de cada sujeito que busca a transexualização não é apaziguadora. Almas não se apaziguam com cirurgias. Elas não se refletem no espelho. 


\section{RESENHAS BIBLIOGRÁFICAS}

\section{Referências}

American Psychiatric Association (2014). DSM-5: Manual Diagnóstico e Estatístico de Transtornos Mentais. Porto Alegre, RS: Artes Médicas.

Organização Mundial da Saúde (1993). Classificação de Transtornos Mentais e de Comportamento da CID-10. Porto Alegre, RS: Artes Médicas.

Citação/Citation: Freire, D. G. (2018, dezembro). Espelho, espelho meu, diga-me de qual sexo sou eu!. Resenha do livro Transexualidade: o corpo entre o suejtio ea ciência. Revista Latinoamericana de Psicopatologia Fundamental, 21(4), 860-863. http://dx.doi. org/10.1590/1415-4714.2018v21n4p860-10.

Editores do artigo/Editors: Profa. Dra. Sonia Leite e Profa. Dra. Marta Regina de Leão D'Agord

Recebido/Received: 12.8.2018 / 8.12.2018 Aceito/Accepted: 24.9.2018 / 9.24.2018

Copyright: (C) 2009 Associação Universitária de Pesquisa em Psicopatologia Fundamental/ University Association for Research in Fundamental Psychopathology. Este é um artigo de livre acesso, que permite uso irrestrito, distribuição e reprodução em qualquer meio, desde que o autor e a fonte sejam citados / This is an open-access article, which permits unrestricted use, distribution, and reproduction in any medium, provided the original authors and sources are credited.

\section{Dercirier Gonçalves Freire}

Psicanalista e Criminóloga; Associada ao Corpo Freudiano Escola de Psicanálise Seção Rio de Janeiro (Rio de Janeiro, RJ, Br); Doutoranda em Psicanálise na Universidade do Estado do Rio de Janeiro - UERJ (Rio de Janeiro, RJ, Br); Mestre em Psicanálise, Saúde e Sociedade pela Universidade Veiga de Almeida - UVA (Rio de Janeiro, RJ, Br). dercirier@hotmail.com

\section{(cc) BY-NC}

This is an open-access article, which permits unrestricted use, distribution, and reproduction in any medium for non-commercial purposes provided the original authors and sources are credited. 